Check for updates

Cite this: RSC Adv., 2018, 8, 31094

\title{
Preparation of self-healing polyurethane/ functionalized graphene nanocomposites as electro-conductive one part adhesives $\uparrow$
}

\begin{abstract}
Farzaneh Hashemi Nasr, (iD a ${ }^{a}$ Mehdi Barikani*b ${ }^{\star b}$ Mehdi Salehirad $^{a}$
We report the synthesis and investigation of the electrical conductivity and self-healing properties of moisture curable polyurethane (PU) adhesives filled with functionalized graphene nanosheets and isophorone diisocyanate (IPDI) loaded poly(methyl methacrylate) (PMMA) nanocapsules. For this purpose, chemically functionalized graphene was prepared by covalently grafting 4-(4,5-diphenyl- $1 \mathrm{H}$-imidazol-2$\mathrm{yl}$ )phenol (DIP) on the surface of graphene oxide and synthesized PMMA nanocapsules were loaded with IPDI. Both nanofillers were then dispersed in a polyurethane matrix and the effects on the adhesion properties of the adhesives in aluminum-aluminum metal joints were studied. The results showed that by surface modification and better exfoliation of graphene nanosheets, the electrical conductivity was increased from $2.2 \times 10^{-9} \mathrm{~S} \mathrm{~m}^{-1}$ to $4.1 \mathrm{~S} \mathrm{~m}^{-1}$ for pure PU and $10 \mathrm{wt} \%$ graphene based nanofiller loaded $\mathrm{PU}$, respectively. The thermal stability, electrical conductivity, shear strength and self-healing process of the ECAs were also studied. The results provide evidence that the prepared adhesives have the potential for applications in electronic device packaging.
\end{abstract}

Received 29th April 2018

Accepted 25th July 2018

DOI: $10.1039 / \mathrm{c} 8 \mathrm{ra03685c}$

rsc.li/rsc-advances

premixed and frozen single-component systems, one part conductive polyurethane adhesives can be efficiently tailored to give a diverse range of products and show more benefits such as flexibility, cost effectiveness, no need for mixing, indefinite pot life with rapid cure at room temperature and a wide application temperature range. ${ }^{12}$

Considering various electrically conductive fillers, graphene related materials have received great research interest for their distinct electrical, optical, thermal, and mechanical properties. ${ }^{13-17}$ Due to the strong intermolecular van der Waals forces existing among graphene nanosheets, achieving homogenous and well exfoliated graphene sheets with single or few layers in both solvents and polymers is challenging. ${ }^{\mathbf{1 8 - 2 0}}$ Therefore, physical and chemical surface modification and functionalization of nanosheets through bulk or solution-based chemical approaches have been employed for higher stabilization of dispersed nanomaterials. $^{21,22}$ In this regard, by simple organic reactions, GO is able to covalently bind with polymers or small molecules and after reduction, functionalized graphene nanosheets can be more compatible with polymer matrixes and organic solvents.

Microcracking and hidden damage can lead to structural failures in polymeric matrixes. In such cases, the use of selfhealing materials will be very beneficial and effective, because of their great potential for the prevention of polymer degradation and reduction of maintenance costs. ${ }^{23,24}$ The concepts of extrinsic and intrinsic self-healing exist for this process. The extrinsic healing is classified into three main groups: capsule based, vascular, and intrinsic based, ${ }^{25}$ in which the embedded healing agents are released after crack formation. In this 
industry, micro/nanocapsule embedment systems were observed to be one of the most effective approaches for the provision of self-healing ability. ${ }^{26}$ Nanocapsules based on polymeric materials can be applied as containers for healants. They can encapsulate a larger quantity of guest substance in their cores and release this on demand at a later stage. ${ }^{27,28}$ In these nanomaterials, healing is promoted by crack propagation through incorporating capsules in the matrix, which then release their contents into crack surfaces. ${ }^{29}$ Isocyanates are a kind of healing material which can develop one-part, catalyst-free self-healing processes while exposed to moist or aqueous environments. ${ }^{30}$ In contrast, intrinsic self-healing is based on reversible covalent ${ }^{31}$ or noncovalent supramolecular interactions ${ }^{32}$ such as $\pi-\pi$ interactions $^{33}$ or hydrogen bonding ${ }^{34}$ and takes place autonomously or with an external trigger like heat or pressure.

In this study, we report the synthesis of IPDI loaded PMMA nanocapsules and DIP functionalized graphene nanosheets for achieving the purposes of self-healing and electrical conductivity for polyurethane adhesives, respectively. Polyurethanes with different structures were prepared from polyols (PEG and PCL) and diisocyanates (HDI and TDI) and the conductive nanofillers and nanocapsules as healing materials were further dispersed into polyurethane matrixes in order to prepare the asmentioned adhesives. The physical properties of the conductive nanofillers, nanocapsules and adhesives were investigated. In addition, the effect of graphene based nanofillers on the shear strength, thermal stability and electrical conductivity properties of ECAs was studied. The efficiency of the self-healing performance based on the nanocapsules and hydrogen bonding interactions is also demonstrated in this study.

\section{Experimental}

\section{Materials and methods}

Graphite flakes (GFs, lateral size $<50 \mu \mathrm{m}$ ), 4-dimethylaminopyridine (DMAP, $99 \mathrm{wt} \%$ ), $N, N$ dicyclohexylcarbodiimide (DCC, $99 \mathrm{wt} \%)$, hydrazine monohydrate ( $80 \mathrm{wt} \%$ ), sodium dodecyl sulfate (SDS, $97 \mathrm{wt} \%$ ), methyl methacrylate (MMA, $99 \mathrm{wt} \%$ ), azobisisobutyronitrile (AIBN, $98 \mathrm{wt} \%$ ), isophorone diisocyanate (IPDI, $98 \mathrm{wt} \%$ ), toluene diisocyanate (TDI, $95 \mathrm{wt} \%$ ), and hexamethylene diisocyanate (HDI, $98 \mathrm{wt} \%$ ) were obtained from Sigma-Aldrich. Potassium permanganate $\left(\mathrm{KMnO}_{4}, 99 \mathrm{wt} \%\right)$, concentrated sulphuric acid $\left(\mathrm{H}_{2} \mathrm{SO}_{4}, 98 \mathrm{wt} \%\right)$, phosphoric acid $\left(\mathrm{H}_{3} \mathrm{PO}_{4}, 85 \mathrm{wt} \%\right)$, hydrochloric acid ( $\left.\mathrm{HCl}, 32 \mathrm{wt} \%\right)$, hydrogen peroxide $\left(\mathrm{H}_{2} \mathrm{O}_{2}, 30 \mathrm{wt} \%\right)$, benzil $98 \mathrm{wt} \%$, 4-hydroxybenzaldehyde $98 \mathrm{wt} \%$, ammonium acetate $\left(\mathrm{NH}_{4} \mathrm{OAC}, 98 \mathrm{wt} \%\right)$, poly ethylene glycol (PEG, BioUltra, $M_{\mathrm{n}}=2000 \mathrm{~g} \mathrm{~mol}^{-1}$ ), glacial acetic acid (HOAC, $99.8 \mathrm{wt} \%)$, $\varepsilon$-caprolactone $99 \mathrm{wt} \%, \mathrm{Sn}(\mathrm{Oct})_{2}$ $92.5 \mathrm{wt} \%$, ethylene glycol $99.8 \mathrm{wt} \%$, ethyl acetate $99.5 \mathrm{wt} \%$, isopropyl alcohol $99.5 \mathrm{wt} \%, N, N$-dimethylformamide (DMF, $99 \mathrm{wt} \%)$, chloroform $99 \mathrm{wt} \%$, and 1,4-dioxane $99.8 \mathrm{wt} \%$ were purchased from Merck Chemicals Co.

\section{Characterization}

The synthesized structures were characterized using FT-IR (Bruker-equinox 55) and ${ }^{1} \mathrm{H}$ NMR (Bruker, $500 \mathrm{MHz}$ ). Thermal properties of adhesives and the content of functional groups grafted to the nanosheets were estimated by thermogravimetric analysis (TGA) with a DuPont Instruments (TGA 951) analyzer at a heating rate of $10{ }^{\circ} \mathrm{C} \min ^{-1}$ in a nitrogen atmosphere. The crystal structures of samples were determined by X-ray diffraction (XRD, X-pert Philips, model no: PW 3040/60) analysis with $\mathrm{Cu} \mathrm{K} \alpha(\lambda=1.54056 \AA)$ radiation. Raman spectra were recorded using a Horiba Jobin Yvon HR800 Raman spectrometer, which was equipped with an $\mathrm{Ar}$ laser (487.97 $\mathrm{nm}, 180 \mathrm{~mW}$ ) as the excitation light source, and an Olympus BX41 microscope. The morphology of the nanosheets was studied by field emission scanning electron microscopy (FE-SEM, HITACHI S-4160). The thickness of the nanosheets was obtained using atomic force microscopy (AFM, Nanowizard II, JPK, Germany). The numberaverage molecular weight $\left(M_{\mathrm{n}}\right)$, weight average molecular weight $\left(M_{\mathrm{w}}\right)$ and polydispersity index (PDI) of polymers were analyzed using gel permeation chromatography (GPC, Agilent GPC 1100). For determination of the shear strength of prepared PU based adhesives, lap shear analysis was used according to ASTM D1002 using a Universal Testing Machine (Instron 5566, USA) in tension, equipped with a $30 \mathrm{kN}$ load cell and the speed was $1.3 \mathrm{~mm} \mathrm{~min}{ }^{-1}$. The volume resistivity $(R)$ of ECA samples was measured using a U-NITUT39A multimeter (0-200 M $\Omega$ ). The absorbance wavelengths of the prepared materials were recorded by UV-Vis spectrophotometry (Perkin Elmer, lambda 800).

\section{Synthesis of GO}

The GO sample was prepared by chemical treatment of natural graphite powder using the improved Hummers method according to the published literature. ${ }^{35}$

\section{Synthesis of DIP- $g$-GO}

DIP was synthesized according to a reported method. ${ }^{36}$ DMAP and DCC can perform the esterification reaction between the carboxylic acid groups within the GO molecular structure and the hydroxyl groups of DIP. First, GO $(0.15 \mathrm{~g})$ was dispersed in DMF by ultrasonication for $30 \mathrm{~min}$. DCC $(2 \mathrm{~g}, 10 \mathrm{mmol})$ and DMAP ( $0.15 \mathrm{~g}, 1.2 \mathrm{mmol})$ were dissolved in DMF and added to the GO nanosuspension at room temperature. After the dissolution of DMAP, DIP (0.5 g, $1.6 \mathrm{mmol})$ was added and the mixture was stirred at $50^{\circ} \mathrm{C}$ for $72 \mathrm{~h}$. To quench the reaction, an equimolar amount of $\mathrm{HCl}$ was added to the mixture to neutralize DMAP. The neutralized DIP- $g$-GO was then precipitated with isopropyl alcohol and DIP-g-GO powder was obtained. The precipitates were obtained by centrifugation at $5000 \mathrm{rpm}$ for $10 \mathrm{~min}$. The product was dried in vacuo at $70^{\circ} \mathrm{C}$ for 12 hours.

\section{Synthesis of DIP-g-rGO}

The chemical reduction of DIP- $g$-GO to DIP- $g$-rGO was accomplished by hydrazine monohydrate similar to the published literature. ${ }^{37}$ DIP-g-GO $(0.15 \mathrm{~g})$ powder was suspended in $50 \mathrm{ml}$ water to give a brown dispersion, and exfoliation was achieved by ultrasonication for $1 \mathrm{~h}$, to eliminate the agglomeration of GO nanosheets at the air/water interface a layer of water-immiscible liquid such as mineral oil was added to the DIP- $g$-GO 
suspension. $^{38}$ The resulting homogeneous dispersion was mixed with $2.5 \mathrm{ml}$ hydrazine solution and heated at $95{ }^{\circ} \mathrm{C}$ for $4 \mathrm{~h}$. After the completion of the reaction, the nanosheets were collected by filtration as a black powder. For further purification, the product was washed with deionized water several times to remove excess hydrazine and dried in vacuo at $70{ }^{\circ} \mathrm{C}$ for 12 hours.

\section{Poly(methyl methacrylate) synthesis (PMMA)}

PMMA was synthesized similarly to a reported process ${ }^{39}$ with some modifications. Briefly, in a round bottom flask equipped with a nitrogen inlet-outlet tube, a water-cooled condenser and a magnetic stirrer, MMA ( $2 \mathrm{~g}, 19 \mathrm{mmol})$ was mixed with AIBN $(0.018 \mathrm{~g}, 0.1 \mathrm{mmol})$ in dioxane $(10 \mathrm{ml})$ as the solvent. The resulting solution was heated at $60{ }^{\circ} \mathrm{C}$ for $14 \mathrm{~h}$ under nitrogen, and after cooling, the mixture was poured into methanol and the formed precipitated high molecular weight polymer chains and suspended low molecular weight ones were separated. For further purification, each part was dissolved in dioxane and precipitated using $n$-hexane ( 3 times). The products were dried in vacuo at $90{ }^{\circ} \mathrm{C}$ for 12 hours.

\section{Synthesis of IPDI loaded PMMA nanocapsules}

Encapsulation of self-healing agents in PMMA nanocapsules occurred by the combination of solvent evaporation and miniemulsion techniques. ${ }^{27}$ Briefly, PMMA (250 mg) and IPDI (250 $\mathrm{mg}$ ) were dissolved in $5 \mathrm{ml}$ chloroform as the oil phase and stirred at $600 \mathrm{rpm}$ for $20 \mathrm{~min}$. Then, the aqueous phase was prepared by the dissolution of $0.03 \mathrm{~g}$ SDS in $30 \mathrm{ml}$ deionized water to give a concentration of $1 \mathrm{mg} \mathrm{ml}^{-1}$. The oil phase was added dropwise to the aqueous solution and an oil-in-water $(\mathrm{O} /$ $\mathrm{W})$ type emulsion was formed by ultrasonication for $2 \mathrm{~min}$. The sample was kept in an ice bath to prevent overheating. Then, the organic solvent was evaporated by stirring in an oil bath at $40{ }^{\circ} \mathrm{C}$ overnight. Finally, the mixture was freeze dried to produce the nanocapsules.

\section{Preparation of one part moisture curable polyurethane adhesives}

For this investigation, different types of prepolymers were synthesized according to the procedures in our previous studies ${ }^{\mathbf{4 0}}$ by the step-growth polymerization of the polyols PEG $\left(M_{\mathrm{n}}=2000 \mathrm{~g} \mathrm{~mol}^{-1}\right)$ and PCL $\left.\left(M_{\mathrm{n}}=5000 \mathrm{~g} \mathrm{~mol}^{-1}\right)\right)$ and the diisocyanates (HDI and TDI). PCL was synthesized according to the literature. ${ }^{41}$ All four different compositions of prepolymers (PU1, PU2, PU3 and PU4) were prepared under the same conditions (Table 2). The polyol was placed into a four-necked reaction kettle equipped with a mechanical stirrer, heating oil bath, reflux condenser, dropping funnel and $\mathrm{N}_{2}$ inlet-outlet. The temperature of the oil bath was increased to $60{ }^{\circ} \mathrm{C}$. Then, diisocyanate was added and the temperature was increased to $90{ }^{\circ} \mathrm{C}$. The molar ratio of polyol to diisocyanate was $1: 1.3$. It almost took $2 \mathrm{~h}$ to obtain NCO-terminated prepolymers. Finally, acetone as the solvent was added to the polyurethane prepolymer and the product was kept tightly closed in a dry place. In all cases, the NCO content of the prepolymer was determined by a di- $n$-butylamine back-titration method according to ASTM D5155.

\section{Fabrication of self-healing electrically conductive adhesives} (ECAs)

For the preparation of ECAs, various amounts of DIP- $g$-rGO nanosheets (3, 7 and $10 \mathrm{wt} \%)$ were dispersed into each PU matrix in acetone by sonication to play the role of a network to provide a carrier transfer pathway. In addition, a constant percentage of IPDI encapsulated PMMA nanocapsules (2.5 wt\%) was added to the matrix to achieve the self-healing ability. Finally, the formulated pastes were manually printed on precleaned glass molds to form samples of $10 \times 10 \mathrm{~mm}$ with a thickness of $1 \mathrm{~mm}$ and then cured at room temperature for $24 \mathrm{~h}$ to prepare the desired PU films.

\section{Results and discussion}

\section{Synthesis and characterization of conductive nanofillers}

In this study, one aim was to synthesize new conductive nanofillers based on graphene with exfoliated layers to be used in conductive adhesives. In this regard, the condensation of benzil with an aromatic aldehyde in the presence of ammonium acetate was adopted as a convenient synthetic method for the preparation of a triaryl imidazole (DIP) (Scheme 1a). Then, the improved Hummers method was used to prepare graphene oxide from pristine graphite. As presented in Scheme 1b, GO nanosheets have reactive oxygen functional groups, such as hydroxyl and epoxy groups on the basal planes and carboxylic acid groups at their edges. Hence, GO nanosheets were successfully functionalized with DIP groups by the Steglich esterification process using DCC and DMAP. Finally, modified graphene oxide (DIP- $g$-GO) was chemically reduced to a colloid state, using hydrazine monohydrate, which resulted in a black precipitate (DIP-g-rGO) from the original yellow-brown GO suspension. Presumably, this is a result of an increase in the hydrophobicity of the material due to the decrease in polar functionality on the surface of the nanosheets. ${ }^{42}$

Raman spectroscopy is an appropriate and powerful tool to determine the structure of graphene-based materials. ${ }^{43}$ According to Fig. 1a, both materials had two characteristic peaks at around $1350 \mathrm{~cm}^{-1}$ (D band) and $1590 \mathrm{~cm}^{-1}$ (G band). For DIP- $g$-GO, the D and $\mathrm{G}$ bands were at $1352 \mathrm{~cm}^{-1}$ and $1599 \mathrm{~cm}^{-1}$, respectively. However, the D band of DIP- $g$-rGO was located around $1347 \mathrm{~cm}^{-1}$, while the corresponding $\mathrm{G}$ mode was shifted to $1589 \mathrm{~cm}^{-1}$. In addition, the $I_{\mathrm{D}} / I_{\mathrm{G}}$ intensity ratio of DIP- $g$-GO had a value of approximately 0.97 , whereas the value for DIP- $g$-rGO was almost 1.04. The increase of the $I_{\mathrm{D}} / I_{\mathrm{G}}$ intensity ratio has been reported for GO after covalent functionalization. ${ }^{44}$ In addition, the increase could be attributed to the partial removal of oxygen moieties and conversion of $\mathrm{sp}^{2}$ carbon atoms in GO to $\mathrm{sp}^{3}$ carbon atoms in graphene. ${ }^{45}$ According to reported results, this may be due to the creation of some structural defects which are produced simultaneously during the reduction process. ${ }^{46,47}$ The observed peaks at $\sim 2700 \mathrm{~cm}^{-1}$ are named the $2 \mathrm{D}$ band in carbon based materials. Consistent 
a)<smiles>O=C(O)c1cccc(C(=O)Nc2ccccc2)c1</smiles>

b)

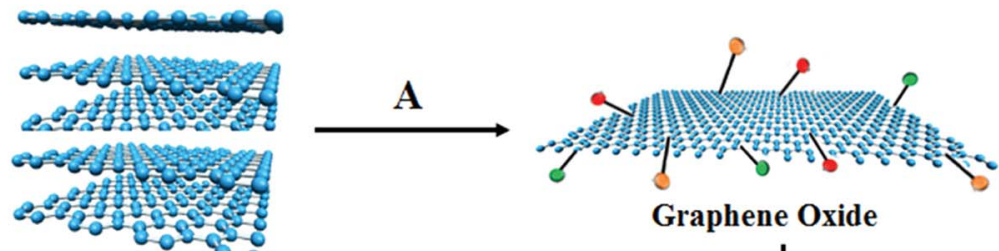

Graphite

B

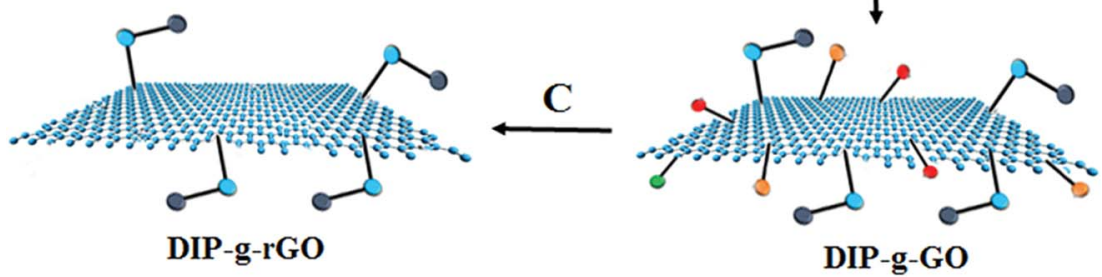

$-\mathrm{OH} \rightarrow-\mathrm{COOH} \rightarrow$

$-\mathrm{CHCH}_{2} \mathrm{O} \rightarrow \quad-\mathrm{DIP} \longrightarrow$

Scheme 1 Synthesis pathways for the preparation of (a) DIP and (b) GO, DIP-g-GO and DIP-g-rGO. (A) $\mathrm{H}_{2} \mathrm{SO}_{4}, \mathrm{H}_{3} \mathrm{PO}_{4}, \mathrm{KMNO}_{4} ;(B)$ DIP, DCC, DMAP; (C) $\mathrm{NH}_{2}-\mathrm{NH}_{2}$.

with the literature, ${ }^{48}$ bilayer sheets or sheets with fewer than five layers show a broader and symmetrical 2D band, whereas bulk graphite or graphene sheets with more than five layers cause the 2D band to split into several overlapping modes. As shown in
Fig. 1a, a broad and symmetrical $2 \mathrm{D}$ band in the $2500-$ $3200 \mathrm{~cm}^{-1}$ region was observed, which indicates that graphene nanosheets with fewer than five layers were obtained in DIP-grGO samples.
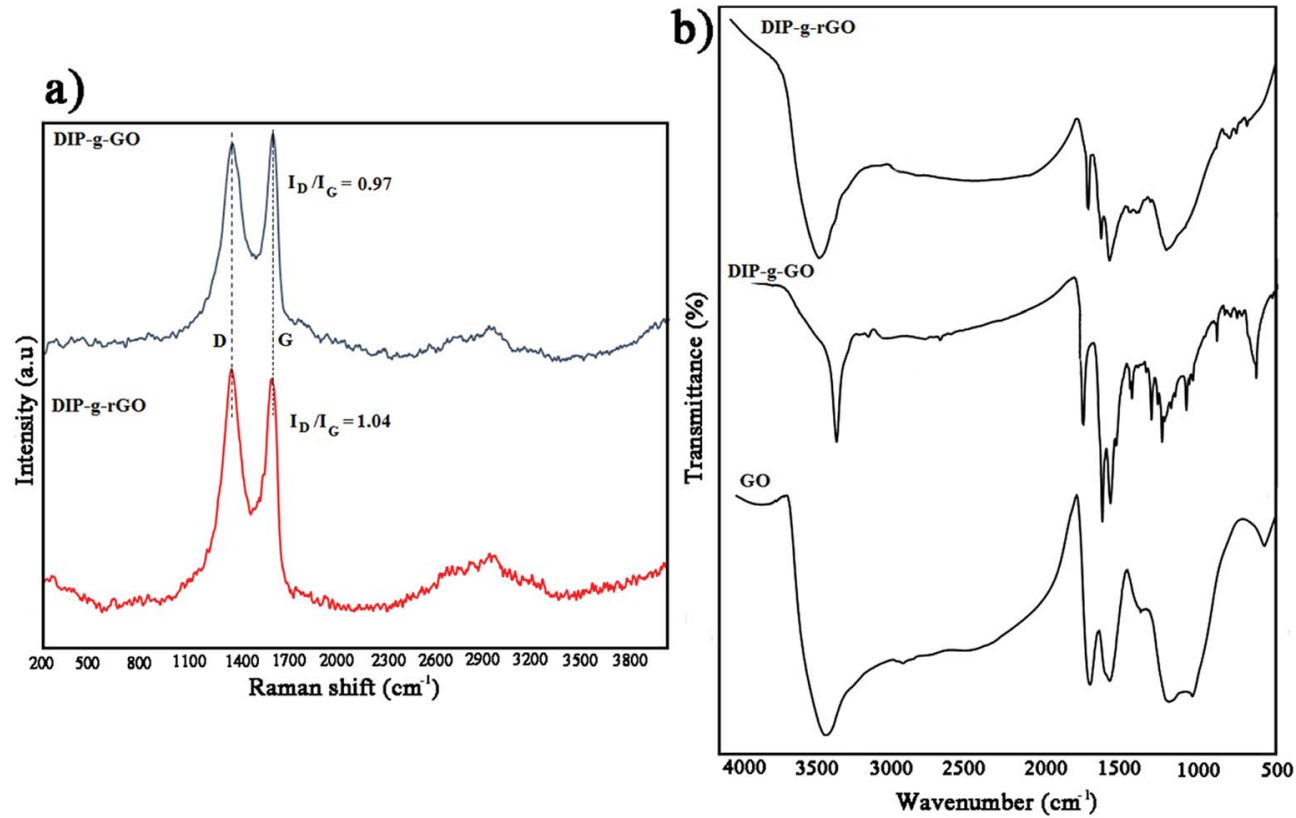

Fig. 1 (a) Raman spectra of DIP-g-GO and DIP-g-rGO and (b) FT-IR spectra of GO, DIP-g-GO and DIP-g-rGO. 
FT-IR analyses were performed to prove the presence of pendant DIP groups in DIP- $g$-GO and DIP- $g$-rGO samples (Fig. 1b). The FT-IR spectrum of GO confirms the formation of hydroxyl, carbonyl, epoxy and alkoxy groups during the oxidation process at $3000-3700 \mathrm{~cm}^{-1}, 1730 \mathrm{~cm}^{-1}, 1217 \mathrm{~cm}^{-1}$ and $1056 \mathrm{~cm}^{-1}$, respectively. ${ }^{35}$ The main absorption bands for DIP were observed at 1065, 1550,1620, 3100 and $3450 \mathrm{~cm}^{-1}$ related to the stretching vibrations of $\mathrm{C}-\mathrm{O}, \mathrm{C}=\mathrm{C}, \mathrm{C}=\mathrm{N}, \mathrm{C}-\mathrm{H}$ and $\mathrm{N}-\mathrm{H}$ bands (Fig. S1a $\dagger$ ). In addition, the assigned ${ }^{1} \mathrm{H}$ NMR spectrum of DIP is shown in Fig. S1b. $\dagger$ As can be seen from Fig. 1b, the appearance of absorption bands at $1750 \mathrm{~cm}^{-1}$ assigned to the stretching vibration of carbonyl groups corroborates the formation of ester groups by the Steglich esterification process in DIP- $g$-GO samples. In addition, the absence of a broad band between $3000-3700 \mathrm{~cm}^{-1}$ related to carboxylic acids in the GO structure and the appearance of a new peak at $3450 \mathrm{~cm}^{-1}(\mathrm{~N}-\mathrm{H})$ confirms the formation of DIP-g-GO. After the reduction reaction, the absence of absorption bands at $1056 \mathrm{~cm}^{-1}$ and $1217 \mathrm{~cm}^{-1}$ indicates the deletion of alkoxy and epoxy groups from the nanosheets. The presence of characteristic peaks of DIP in the DIP- $g$-rGO spectrum proves that the grafted DIP was not considerably affected by hydrazine.

The XRD patterns of GO, DIP- $g$-GO, DIP and DIP- $g$-rGO are shown in Fig. S2. $\dagger$ The diffraction peak at $2 \theta=26.71^{\circ}$ with a $d$ spacing of $0.34 \mathrm{~nm}$ was assigned to the crystalline and characteristic (002) reflection of pristine GF. After the oxidation reaction, the considerable shift of the (002) reflection from $0.34 \mathrm{~nm}$ to $0.70 \mathrm{~nm}$ proves the formation of GO nanosheets (Fig. S2a $\dagger$ ). The increase in the $d$ spacing of GO compared to GF is due to the incorporation of various oxygen functional groups in between the (002) planes of GF. After DIP attachment on GO nanosheets, the $(002)$ reflection shifted to a lower value $(2 \theta=$ $8.85^{\circ}$ ) and the $d$ spacing increased to $1.01 \mathrm{~nm}$, indicating that the introduction of DIP groups gave rise to the interlayer spacing of the GO nanosheets (Fig. S2b $\dagger$ ). In the case of DIP- $g$ rGO, the absence of a peak at $8.85^{\circ}$ and the appearance of a new reflection at $25.4^{\circ}$ confirmed the successful reduction reaction due to the removal of water and other oxygenated functional groups from the GO surface (Fig. S2d $\dagger$ ). ${ }^{42}$

TGA analysis was used to investigate thermal stability and the grafting ratio of functional groups on synthesized structures, as shown in Fig. 2 (left). In the TGA curve of GO, there is about a $12 \mathrm{wt} \%$ weight loss below $160{ }^{\circ} \mathrm{C}$, and a major weight loss of about $20 \mathrm{wt} \%$ between 100 and $250^{\circ} \mathrm{C}$ which correspond to the removal of absorbed water and the release of $\mathrm{CO}$ and $\mathrm{CO}_{2}$ from the most labile functional groups. Between 250 and $600^{\circ} \mathrm{C}$, a slower mass loss was observed which can be attributed to the removal of more stable oxygenated functional groups. ${ }^{35}$ The decomposition temperature for DIP was about $210{ }^{\circ} \mathrm{C}$ (Fig. S3†), which overlapped with the release temperature of oxygenated functional groups in the case of DIP-g-GO. The improved thermal stability of GO after modification is due to the inter and intramolecular interactions of GO and DIP. As observed in the TGA curve, a weight loss of about $70 \mathrm{wt} \%$ starts to appear at a higher peak temperature about $\sim 230{ }^{\circ} \mathrm{C}$ to $600{ }^{\circ} \mathrm{C}$. According to these data, there was about $33.3 \mathrm{wt} \%$ of DIP and $66.7 \mathrm{wt} \%$ of GO in DIP-g-GO structures. Due to the elimination of oxygen containing groups through the reduction process, the weight loss of DIP-g-rGO was mostly related to the loss of DIP ( 30 wt $\%)$.

In order to obtain morphological information for DIP- $g$-GO and DIP- $g$-rGO, FE-SEM observations were conducted. As illustrated in Fig. 2 (right), DIP-g-GO nanosheets exhibited uniform flakes with a few wrinkles and protrusions with many small dots, which correspond to DIP groups. In some regions, a little folding and sticking was observed which is due to the
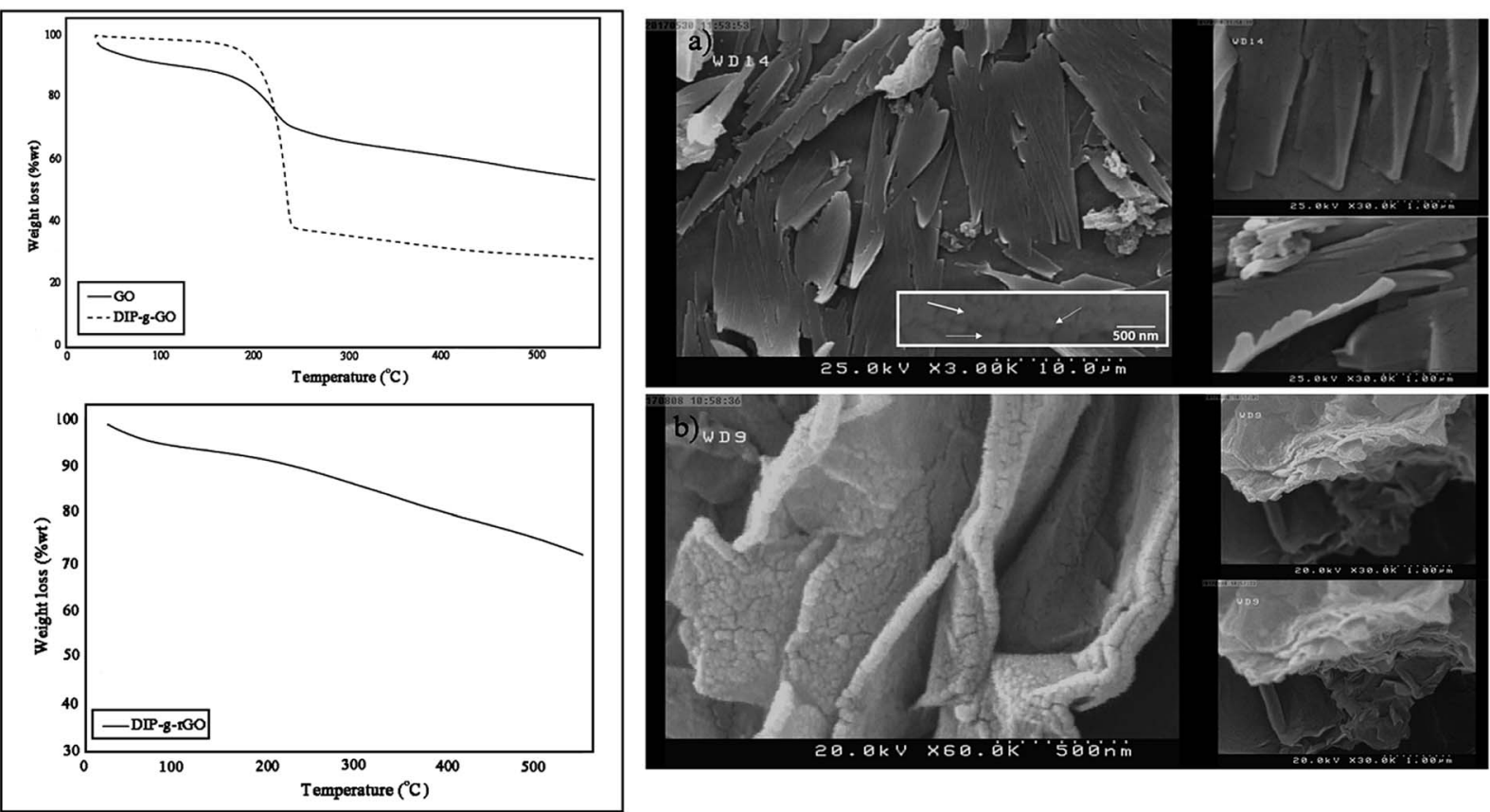

Fig. 2 TGA thermograms of GO, DIP-g-GO and DIP-g-rGO (left) and SEM images of (a) DIP-g-GO and (b) DIP-g-rGO (right). 
intermolecular interactions between oxygenated functional groups and the amine group in the imidazole ring. After the reduction process, the surfaces of nanosheets became rough and debundled which demonstrates that the surfaces of DIP- $g$ rGO nanosheets were still densely functionalized by small sized groups, which is the evidence for DIP molecules on the nanosheets.

AFM was used in tapping mode to determine the thickness as a criterion of the exfoliation degree of nanosheets (Fig. 3). The height profile shown in Fig. 3a is related to GO with an average thickness of about $1 \mathrm{~nm}$ which is in accordance with published studies. ${ }^{49-51}$ On the basis of AFM measurements on DIP- $g$-GO, the nanosheets were of a similar size to the GO sheets, but they were much thicker than GO (4-5 nm). This clearly demonstrates that the presence of DIP groups on the surface of GO nanosheets resulted in much more intermolecular interaction between GO nanosheets due to the presence of hydroxyl, carboxyl and amine groups of GO and DIP, respectively. In contrast, the AFM height image for DIP- $g$-rGO provides convincing evidence that individual graphene nanosheets with a thickness of 1-1.2 nm could be prepared by chemical reduction of surface functionalized GO nanosheets.

\section{PMMA and PMMA based nanocapsule characterization}

The molar mass averages of the number $\left(M_{\mathrm{n}}\right)$ and weight $\left(M_{\mathrm{w}}\right)$ and polydispersity index (PDI) of the synthesized PMMA were determined by GPC (Table 1). The GPC curves are shown in Fig. S4. $\dagger$

IPDI loaded nanocapsules were prepared by a general and facile method achieved by the combination of solvent evaporation and miniemulsion techniques. To evaluate the properties

Table 1 Molecular weights and PDIs of prepared structures

\begin{tabular}{llll}
\hline Polymer & $M_{\mathrm{n}}\left(\mathrm{g} \mathrm{mol}^{-1}\right)$ & $M_{\mathrm{w}}\left(\mathrm{g} \mathrm{mol}^{-1}\right)$ & PDI \\
\hline PMMA-LMW & 7148 & 9645 & 1.34 \\
PMMA-HMW & 21969 & 29637 & 1.34
\end{tabular}

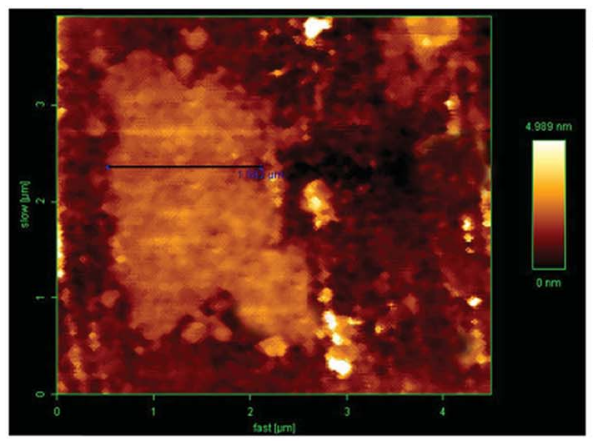

a)
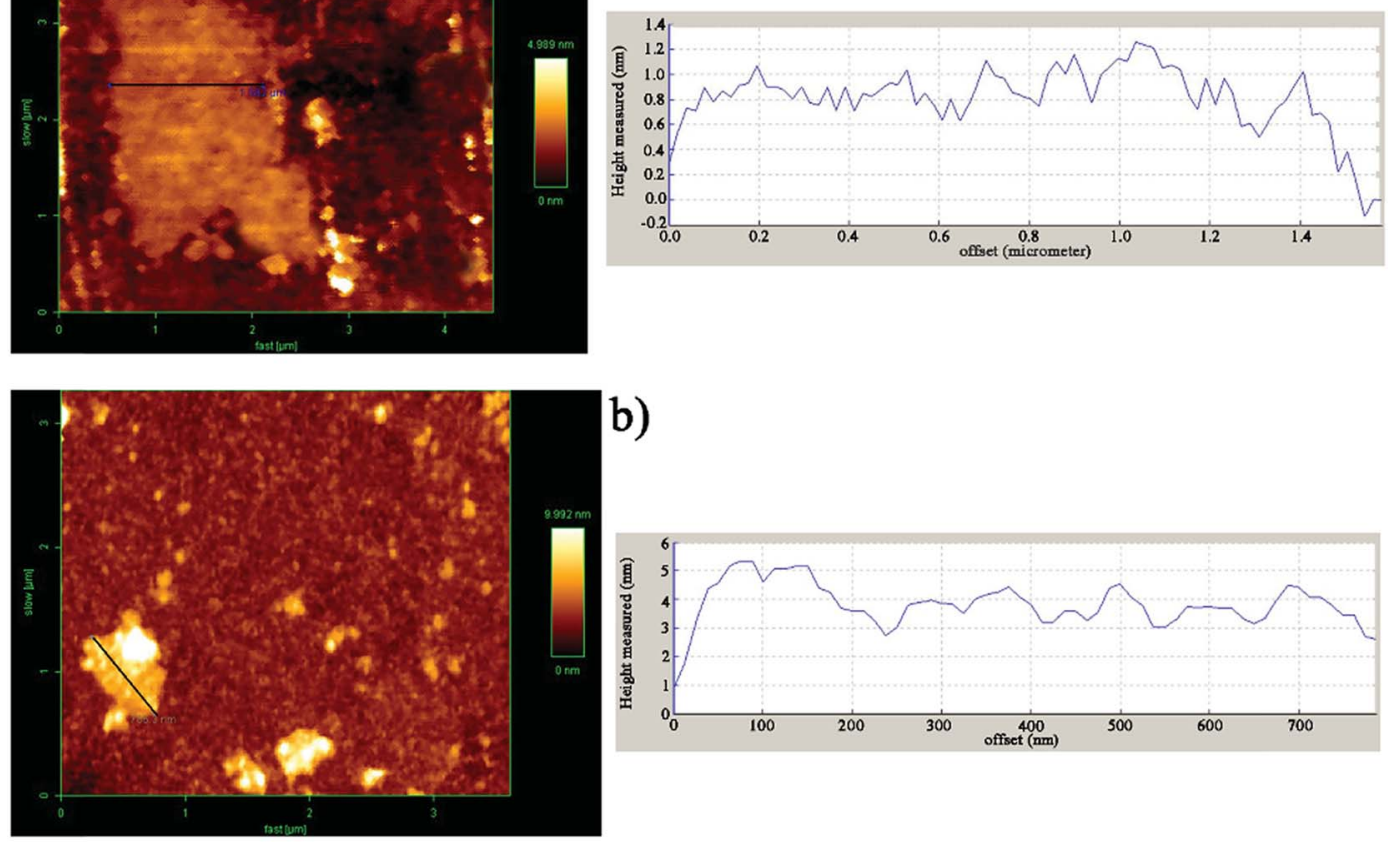

b)
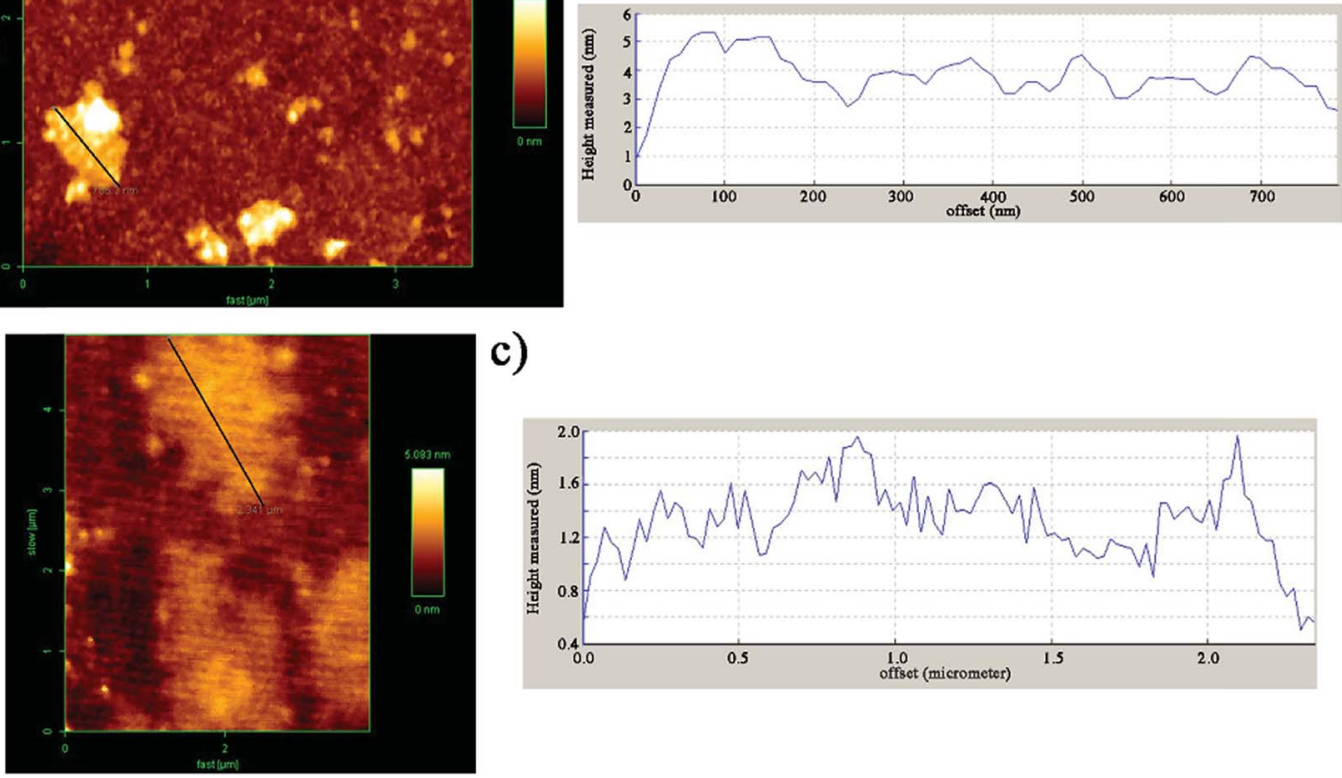

c)

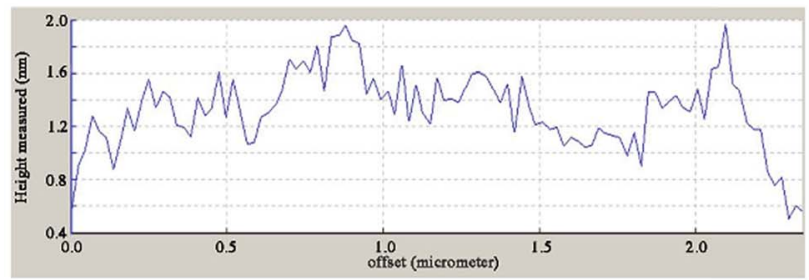

Fig. 3 AFM images and corresponding height profiles of (a) GO, (b) DIP-g-GO and (c) DIP-g-rGO. 
of the nanocapsules, the morphology of PMMA-LMW and PMMA-HMW based nanocapsules was investigated using FESEM (Fig. 4). As shown in Fig. 4a, the preparation conditions and surfactant content for LMW nanocapsules are appropriate and the nanocapsules are spherical and stable with noncollapsed structures. In contrast, this method was not appropriate for HMW nanocapsules as these were aggregated due to the lack of enough surfactant. Hence, PMMA-LMW nanocapsules were used for self-healing purposes.

The chemical structure of IPDI loaded PMMA-LMW nanocapsules was investigated using FT-IR. Based on Fig. 4b, in addition to the main PMMA absorption bands at 1150-1275, 1393, 1735, 2957, 2996 and $3452 \mathrm{~cm}^{-1}$ related to the stretching vibrations of $\mathrm{C}-\mathrm{O}-\mathrm{C}$, $\alpha$-methyl groups, $\mathrm{C}=\mathrm{O}, \mathrm{CH}_{2}, \mathrm{CH}_{3}$ and $-\mathrm{OH}$ (physisorbed moisture), the large -NCO stretching peak at $2259 \mathrm{~cm}^{-1}$ confirmed that IPDI was encapsulated in the nanocapsules.

\section{Preparation of one part moisture curable polyurethane} adhesives

NCO terminated PUs were synthesized through a prepolymerization method using different polyols and diisocyanates (Scheme 2a).

The formulations used for preparing moisture curable PUs are given in Table 2 . The experimental values of NCO content of the prepolymers were also determined and found to be close to the theoretical values.

\section{Fabrication of self-healing and electrically conductive adhesives}

Scheme $2 \mathrm{~b}$ illustrates the preparation process of self-healing ECAs in this study. At first, a PU acetone solution and DIP- $g$ -
rGO acetone suspension were mixed together in a certain ratio. Then, IPDI loaded PMMA nanocapsules in a constant amount were added and stirred at room temperature after complete mixing. Finally, the formulated pastes were manually printed on pre-cleaned glass molds and cured at room temperature for the preparation of the one part adhesives.

FT-IR analysis was performed to detect the formation of urethane linkages by the reaction between polyols and diisocyanates through monitoring the absorption peaks of $-\mathrm{NH}$ and -CO at $\sim 3350$ and $\sim 1720 \mathrm{~cm}^{-1}$, indicating the synthesis of a product which has -NHCOO groups (Fig. 5). In addition, the disappearance of the peak at $\sim 2260 \mathrm{~cm}^{-1}$ (NCO) in all samples confirmed that the urethane prepolymers had an average isocyanate functionality which was sufficient to allow the preparation of crosslinked polyurethanes upon curing with moisture. Free NCO groups would yield amines and $\mathrm{CO}_{2}$ in the presence of moisture that in turn would lead to polymerization and self-healing reactions.

\section{Shear strength investigation via lap shear testing}

The shear strength of adhesively bonded metal plates $(108 \mathrm{~mm}$ $\times 25.4 \mathrm{~mm} \times 1.62 \mathrm{~mm}$ ) for PU1-PU4 was evaluated by means of standard test method ASTM D1002. Adhesive joints were pulled together by pressing the two plate surfaces coated with the degassed PU adhesives to make a lap area of $25.4 \mathrm{~mm} \times 12.5$ $\mathrm{mm}$. Shear strength, reported in units of shear stress was calculated according to eqn (1):

$$
\text { Shear strength }=\text { failure load/adhesive lap area }
$$

As can be seen from Fig. 6, the chemical structure and molecular weight of components are important factors for the
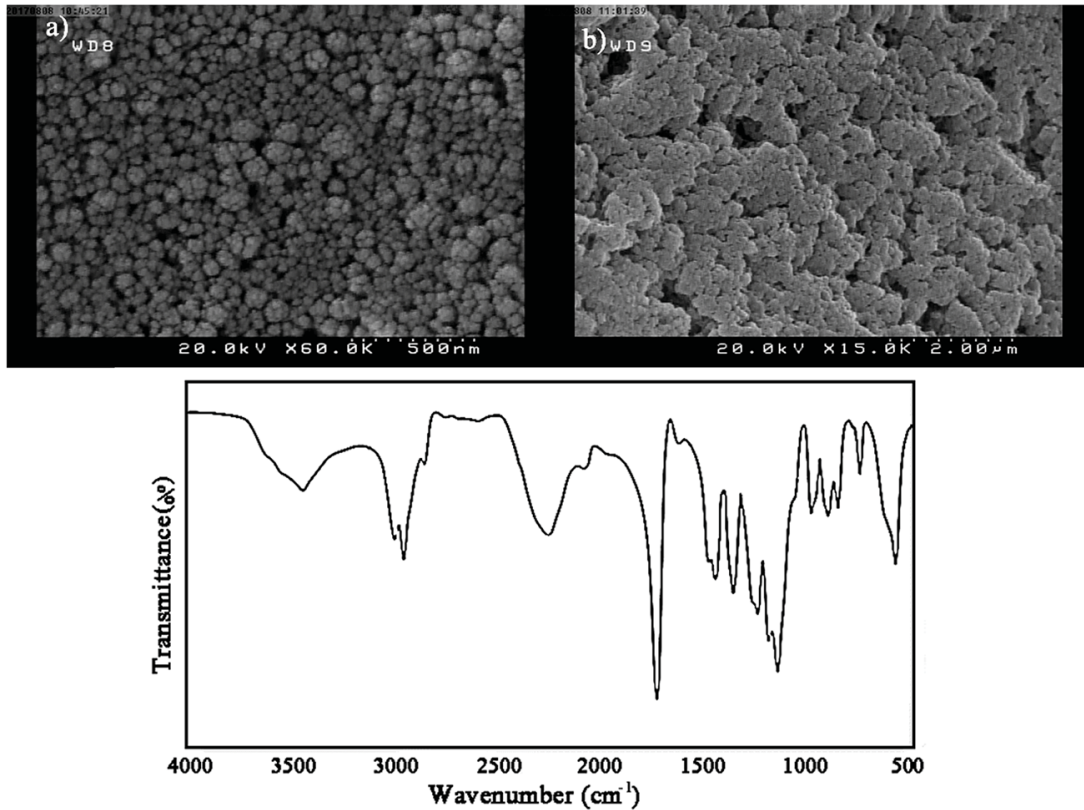

Fig. 4 ( $(a$ and b) Representative SEM micrographs of the prepared nanocapsules and (c) FT-IR spectrum of IPDI loaded PMMA-LMW nanocapsules. 

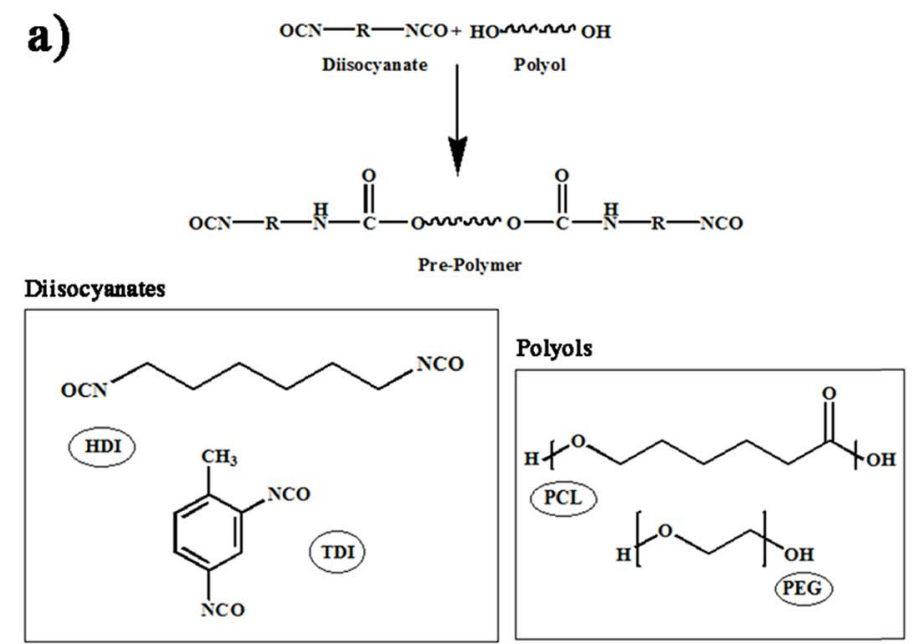

b)
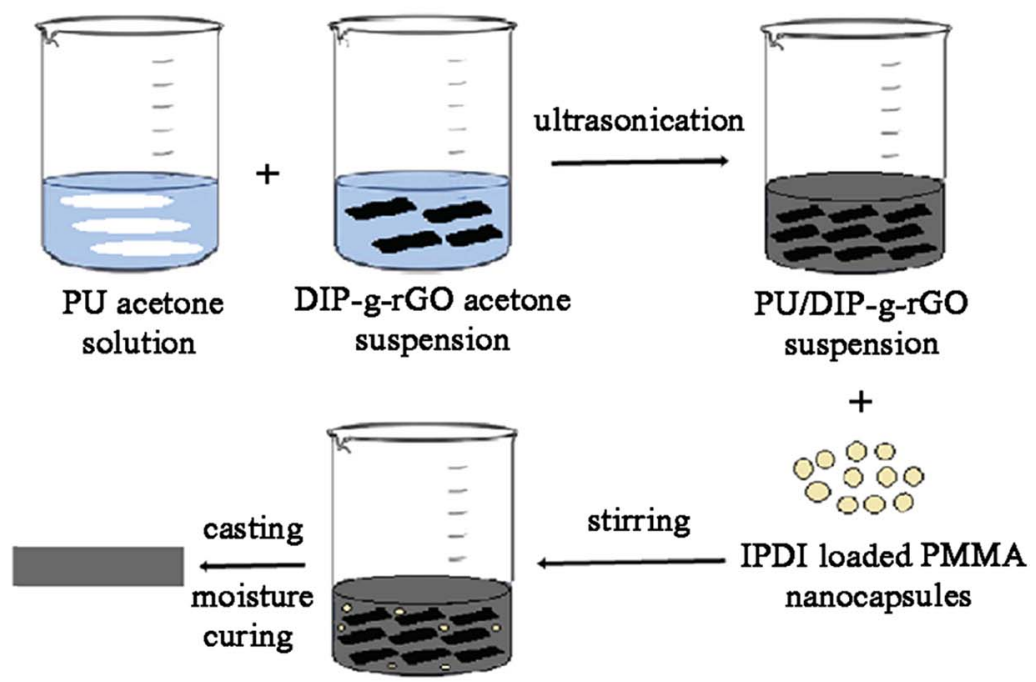

Scheme 2 Synthesis procedure for (a) one-part PU adhesives and (b) self-healing ECAs.

Table 2 Formulation and values of NCO content for the prepared PUs

\begin{tabular}{|c|c|c|c|c|c|c|}
\hline \multirow[b]{2}{*}{ Sample codes } & \multicolumn{2}{|l|}{ NCO content } & \multirow[b]{2}{*}{ PEG (g) } & \multirow[b]{2}{*}{ PCL (g) } & \multirow[b]{2}{*}{ HDI $(g)$} & \multirow[b]{2}{*}{ TDI $(\mathrm{g})$} \\
\hline & Experimental & Theoretical & & & & \\
\hline PU2 & 7.81 & 7.78 & 3.33 & - & 0.73 & - \\
\hline PU3 & 8.55 & 8.51 & 3.00 & 0.33 & - & 0.75 \\
\hline PU4 & 10.60 & 10.56 & 3.00 & 0.33 & 0.73 & - \\
\hline
\end{tabular}

adhesion of PU1-PU4 to the metal surface. The maximum loads for PU1-PU4 were 441.96, 420.05, 547.68 and $504.19 \mathrm{~N}$, respectively. The shear strength test results showed that the adhesion strength of all the kinds of adhesive were in the range from 1.32 to $1.72 \mathrm{MPa}$, depending on the structure of the polyol and the diisocyanate. The highest shear strength was observed for PU3 which is mainly due to the increase in the number of $\mathrm{OH}$ groups of the adhesive due to the presence of two different polyols in its structure in comparison to PU1 and PU2. In addition, as aromatic isocyanates (TDI) give more rigid PUs than aliphatic ones (HDI), PU3 showed enhanced mechanical properties compared to PU4. According to these results, PU3 was selected in an optimized formulation for PU-ECAs. The shear strength of PU3 based adhesives containing 3, 7 and $10 \mathrm{wt} \%$ DIP- $g$-rGO nanosheets and $2.5 \mathrm{wt} \%$ IPDI loaded nanocapsules was also tested. Compared with neat PU3, the shear strength was enhanced from 1.755 MPa to $1.931 \mathrm{MPa}$ when the graphene based nanosheet loading increased from 3 to $10 \mathrm{wt} \%$. This increase may result from the increased interaction between hydroxyl groups on the metal surface, oxygen and nitrogen 


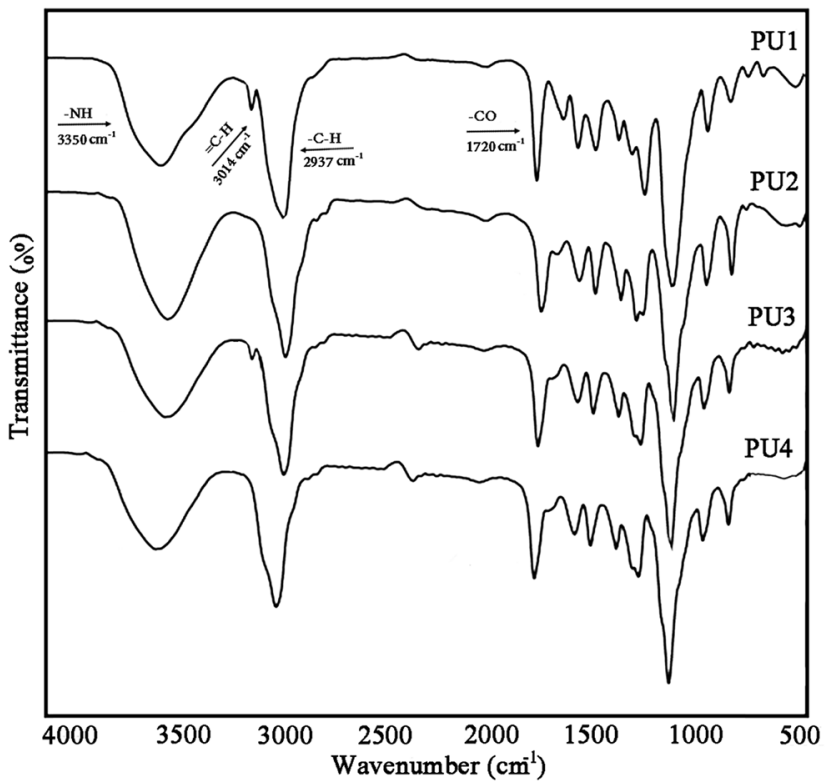

Fig. 5 FT-IR spectra of moisture cured polyurethanes (PU1-PU4).

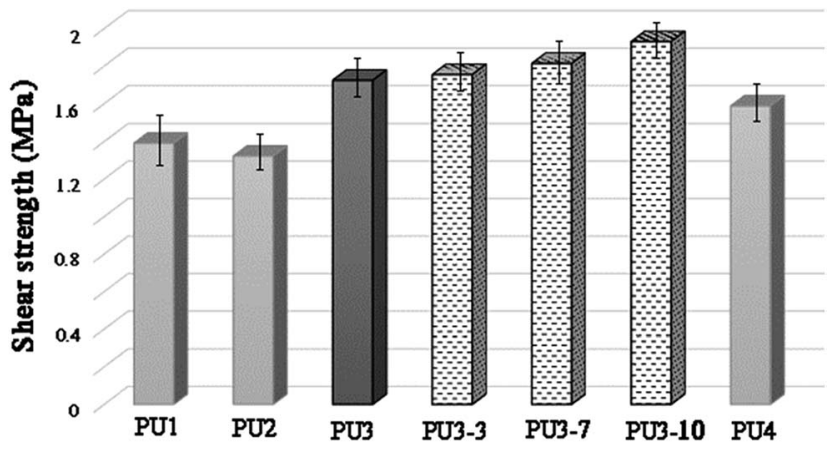

Fig. 6 Lap shear test results of PU1-PU4 and PU3 based ECAs.

functionalities on the graphene based nanofiller and the PU matrix that helps with the interfacial strength.

\section{Thermal stability of ECAs}

A comparison of the TGA curves of three different types of ECA based on PU3 is shown in Fig. 7. The amount of IPDI loaded PMMA nanocapsules was constant $(2.5 \mathrm{wt} \%)$ in all samples. As illustrated in this figure, for all of the ECA samples, the thermal stability and remaining ash were higher than those of neat PU3. According to the literature ${ }^{52}$ the early stage degradation for PU occurred mainly in hard segments where urethane groups first undergo depolymerization, which results in individual monomers, and then, their further reaction produces carbon dioxide. The TGA curves showed that the degradation of PU started at about $260{ }^{\circ} \mathrm{C}$ and ended at $600{ }^{\circ} \mathrm{C}$. The major decomposition of PMMA occurred in the temperature range $270-450{ }^{\circ} \mathrm{C}(\sim 85 \%)$ which is attributed to main chain scission..$^{53}$ The mass loss onset point of IPDI as the core material is nearly $125{ }^{\circ} \mathrm{C} .{ }^{54} \mathrm{After}$ high temperature treatment, neat PU3 has $\sim 2.5 \mathrm{wt} \%$ residual, while the residual for ECA nanocomposites was around 10.3, 19.6, and $25.5 \mathrm{wt} \%$, for 3,7 and $10 \mathrm{wt} \%$ nanofiller, respectively which suggests the good stability of ECAs. The results showed that the temperature of maximum weight loss rate increased with the increase of nanofiller content. It was found that the thermal stability of these samples gradually improved, which is possibly because the interaction between DIP- $g$-rGO nanosheets and PU matrix at high content can effectively restrict the movement of PU chains. In fact, the physical interactions between both oxygenated groups on the graphene nanosheets and -NH functionalities on the grafted DIP with the PU3 matrix may lead to the formation of physical crosslinking between the nanofiller and polymer chains and an increase in char residues.

\section{Electrical conductivity measurements}

The conductive behavior of DIP- $g$-rGO based adhesives drove us to explore the effects of the nanofiller on the conductivity of the resulting ECAs. The electrical conductivity of moisture-cured adhesives was obtained by the following equation (eqn (2)):

$$
\rho=l / R S=l / R t w
$$

where $R, S, l, w$, and $t$ are the volume resistivity, cross sectional area, length, width, and thickness of the sample, respectively. As shown in Fig. 8, for pure PU3, the electrical conductivity was $2.2 \times 10^{-9} \mathrm{~S} \mathrm{~m}^{-1}$, lower than all the ECAs based on PU3. The electrical conductivity of ECAs was seen to increase with the increase of DIP-g-rGO content. In fact, the conductivity enhanced from $1.3 \times 10^{-6}$ to $4.1 \mathrm{~S} \mathrm{~m}^{-1}$ when the nanofiller weight ratio increased from $3 \mathrm{wt} \%$ to $10 \mathrm{wt} \%$. In comparison with a study by $\mathrm{Yu}$ et al., the value of EC for 7-8 wt\% graphene nanoplatelet loading was around $0.1 \mathrm{~S} \mathrm{~m}^{-1}$ which is lower than that of our results $\left(0.7 \mathrm{~S} \mathrm{~m}^{-1}\right){ }^{55}$ The results clearly demonstrate that the homogeneous dispersion of nanofiller in the polymer matrix can significantly improve the conducting capability of all the investigated adhesives due to the construction of connected nanosheet networks and thus successful conductive pathways. In contrast to the published literature, ${ }^{56}$ the grafted organic molecules (DIP groups) not only are not a barrier for graphene conductive networks, but also lead to an increase in conductivity by improvements in the interfacial charge transfer process. The results can be explained by the UV-Vis analysis (Fig. S5 $†$ ). To the best of our knowledge, this is the first time that this property has been studied by UV-Vis. According to the spectra (Fig. S5a $\dagger$ ), there are two characteristic absorption bands in the spectrum of GO at $232 \mathrm{~nm}$ and $298 \mathrm{~nm}$ attributed to $\pi-\pi^{*}$ transitions of $\mathrm{C}=\mathrm{C}$ bonds and $\mathrm{n}-\pi^{*}$ transitions of $\mathrm{CHO}$ bonds, respectively. The DIP compound exhibited a high energy absorption band with maxima from $205 \mathrm{~nm}$ to $300 \mathrm{~nm}$ which can be attributed to $\pi-\pi^{*}$ transitions resulting from conjugation between the aromatic rings and nitrogen atoms (data not shown). After the preparation of DIP-g-rGO (Fig. S5b $\dagger$ ), three absorption peaks at 212, 231 and $303 \mathrm{~nm}$, corresponding to DIP absorption in the ultraviolet region, were observed in the spectrum which confirmed the presence of DIP groups. Also, the absorption band at $298 \mathrm{~nm}$ was completely removed which confirmed the elimination of oxygen containing functional 


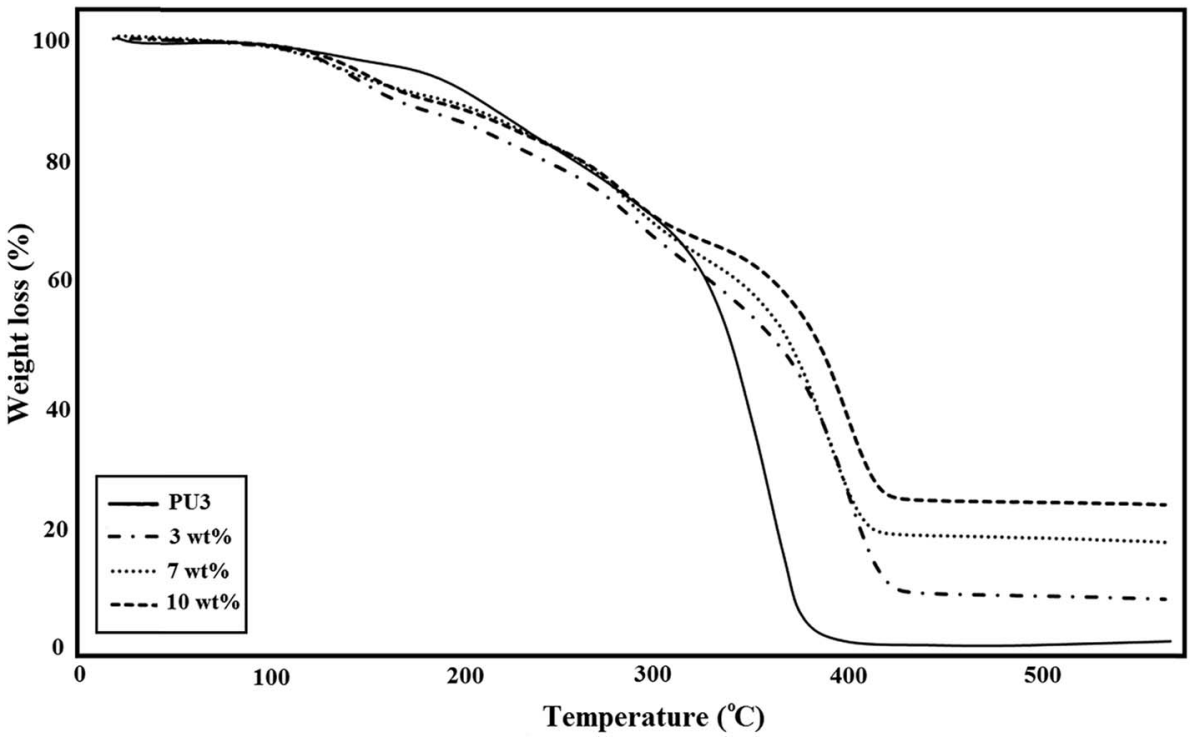

Fig. 7 TGA thermograms of ECAs based on PU3 with different DIP-g-rGO loadings.

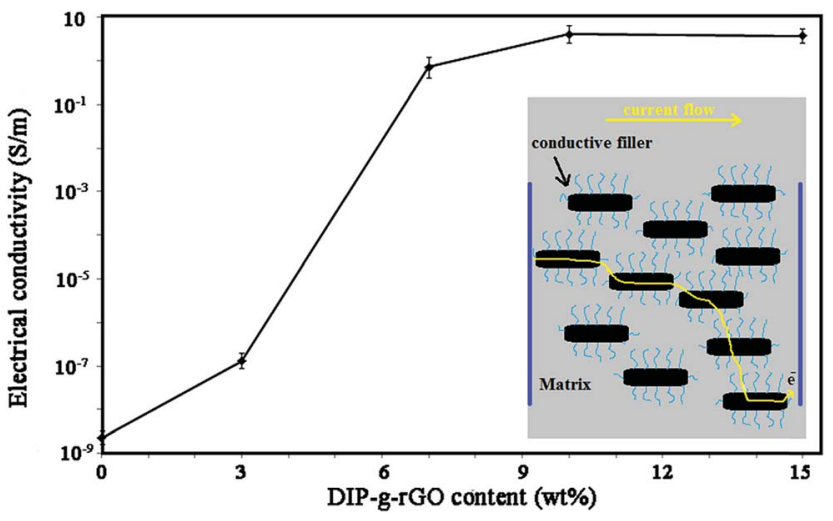

Fig. 8 Electrical conductivity of DIP-g-rGO based ECAs with different loadings. groups on the surface of GO during the reduction process. ${ }^{57}$ In addition, the characteristic absorption peak for graphene at $262 \mathrm{~nm}$ redshifts to $268 \mathrm{~nm}$ as a result of possible electrontransfer from the DIP moiety, an electron donor, to $\mathrm{rGO}$, an electron acceptor. Therefore, the incorporation of DIP functional groups on graphene can prevent the restacking of graphene nanosheets, and improve the interfacial charge transfer process. However, the conductivity decreased when the content of nanofiller reached $15 \mathrm{wt} \%$. It seems that by increasing the content of conductive nanofiller, fewer effective conductive networks will be formed and at the same time, the contact points among conductive fillers will be increased which are due to the agglomeration of nanofillers. ${ }^{13}$ In summary, the optimum amount of the conductive nanofiller was shown to be $10 \mathrm{wt} \%$.
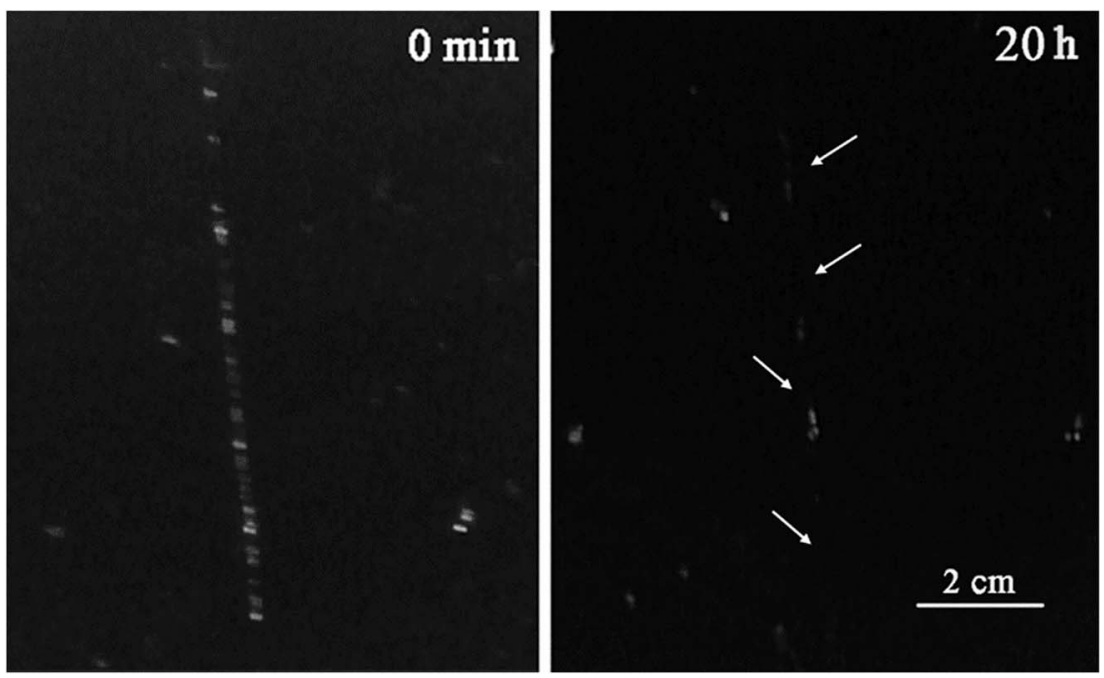

Fig. 9 Self-healing test for a PU3 based ECA containing 10 wt\% DIP-g-rGO and 2.5 wt\% IPDI loaded nanocapsules. 


\section{Self-healing properties of prepared adhesives}

A few articles describe the usage of micro or nano containers as self-healing agents especially in polyurethane matrixes, because polymers with urethane units are recognized as materials with self-healing properties. ${ }^{58}$ In order to investigate the self-healing behavior of ECAs, the evolution of cracks was observed qualitatively. A sample (PU3 containing $10 \mathrm{wt} \%$ DIP-g-rGO and $2.5 \mathrm{wt} \%$ IPDI loaded nanocapsules) as a dry $100 \mu \mathrm{m}$ film was prepared and damaged with a paper knife to create a crack with $0.5 \mathrm{~mm}$ depth. It was stored in a climate chamber at $25{ }^{\circ} \mathrm{C}$ and $50 \%$ relative humidity $(\mathrm{RH})$ and the crack evolution process was observed, as shown in Fig. 9. It was seen that the width of the crack disappeared completely when the time reached $20 \mathrm{~h}$. In this experiment, two types of self-healing process (extrinsic and intrinsic) occurred which led to the reduction in self-healing time. In the extrinsic healing system, healing agent (IPDI) was embedded in PMMA nanocapsules that was released after crack formation. The encapsulated material, a monomeric aliphatic diisocyanate, is reactive with moisture and can be applied as an appropriate healing agent to synthesize one-part, catalyst-free self-healing materials. ${ }^{59}$ The intrinsic self-healing was performed by hydrogen bonding autonomously in the presence of moisture. The water molecules act as a plasticizer in polymer matrixes and lower the network density causing a plasticization effect by increasing the molecular dynamics of hydrogen bonding processes. ${ }^{60}$ The absorbed water molecules in polymeric matrixes can be present in three different states: bound to the polymeric chain, weakly bound water, and free water. ${ }^{61}$ Due to the presence of oxygenated and $-\mathrm{NH}$ functionalities on the graphene nanosheets and grafted DIP, respectively in the PU3 matrix, the ability to absorb moisture will be increased and as a result the self-healing time will be decreased.

\section{Conclusion}

In summary, different moisture curable PU based adhesives were prepared and the one with the highest adhesion strength was adopted for use as an electrically conductive and selfhealing adhesive. In this regard, functionalized graphene nanosheets as the conductive nanofiller and IPDI loaded PMMA nanocapsules were synthesized to be dispersed in the PU matrix to achieve these as-mentioned purposes. We found that the shear strength was mainly dependent on the chemical structure of PU and the nanofiller, which is the result of interaction between hydroxyl groups on the metal surface, oxygen, and nitrogen functionalities on the graphene based nanofiller and PU matrix that helps with the interfacial strength. In addition, by using the modification approach, we were able to facilitate the dispersion of graphene nanosheets inside the polymer matrix, which resulted in improvements to the thermal and electrical properties of ECAs at low filler content. The selfhealing test result showed that the presence of conductive nanofillers would help the healing process due to an increase in the moisture absorption ability. The prepared adhesive has the potential application to be used as a flexible packaging material in power electronic and microwave applications, or as a conductive paste for wearable radio-frequency devices, chip bonding and thermal interface materials.

\section{Conflicts of interest}

There are no conflicts to declare.

\section{Acknowledgements}

The authors want to express their sincere gratitude to Iran's National Elites Foundation (INEF), the Niroo Research Institute (NRI) and the Iran Polymer and Petrochemical Institute (IPPI) for financially supporting this work.

\section{References}

1 L. Bauermann, E. Fokuhl, S. Stecklum, D. Philipp, T. Geipel, A. Kraft, U. Eitner, T. Fischer and D. Breitenbücher, Energy Procedia, 2017, 124, 554-559.

2 K. Suzuki, O. Suzuki and M. Komagata, IEEE Trans. Compon., Packag., Manuf. Technol., Part A, 1998, 21, 252-258.

3 E. Messina, N. Leone, A. Foti, G. Di Marco, C. Riccucci, G. Di Carlo, F. Di Maggio, A. Cassata, L. Gargano, C. D’Andrea, B. Fazio, O. M. Maragò, B. Robba, C. Vasi, G. M. Ingo and P. G. Gucciardi, ACS Appl. Mater. Interfaces, 2016, 8, 2324423259.

4 Y. Li, K. Moon and C. Wong, Nano-conductive Adhesives for Nano-electronics Interconnection, Nano-Bio-Electronic, Photonic and MEMS Packaging, ed. C. Wong, K. S. Moon and Y. Li, Springer, Boston, 2010.

5 J. Luo, Z. Cheng, C. Li, L. Wang, C. Yu, Y. Zhao, M. Chen, Q. Li and Y. Yao, Compos. Sci. Technol., 2016, 129, 191-197.

6 Y. Li and C. P. Wong, Mater. Sci. Eng., R, 2006, 51, 1-35.

7 I. Mir and D. Kumar, Int. J. Adhes. Adhes., 2008, 28, 362-371.

8 Z. A. Ghaleb, M. Mariatti, Z. M. Ariff and J. Ervina, J. Mater. Sci.: Mater. Electron., 2018, 29, 3160-3169.

9 H. Kishi, S. Tanaka, Y. Nakashima and T. Saruwatari, Polymer, 2016, 82, 93-99.

10 J. Gu, C. Liang, X. Zhao, B. Gan, H. Qiu, Y. Guo, X. Yang, Q. Zhang and D. Y. Wang, Compos. Sci. Technol., 2017, 139, 83-89.

11 A. Q. Barbosa, L. F. M. da Silva, J. Abenojar, M. Figueiredo and A. Öchsner, Composites, Part B, 2017, 114, 299-310.

12 Z. Li, R. Zhang, K. Moon, Y. Liu, K. Hansen, T. Le and C. P. Wong, Adv. Funct. Mater., 2013, 23, 1459-1465.

13 H. Ma, M. Ma, J. Zeng, X. Guo and Y. Ma, Mater. Lett., 2016, 178, 181-184.

14 Y. Lai and N. Tai, ACS Appl. Mater. Interfaces, 2015, 7, 1855318559.

15 H. Kim and S. Lee, Fibers Polym., 2017, 18, 1304-1313.

16 Y. Guo, G. Xu, X. Yang, K. Ruan, T. Ma, Q. Zhang, J. Gu, Y. Wu, H. Liu and Z. Guo, J. Mater. Chem. C, 2018, 6, 30043015.

17 M. Casa, M. Sarno, R. Liguori, C. Cirillo, A. Rubino, E. Bezzeccheri, J. Liu and P. Ciambelli, J. Nanosci. Nanotechnol., 2018, 18, 1176-1185. 
18 W. Ai, J. Liu, Z. Du, X. Liu, J. Shang, M. Yi, L. Xie, J. Zhang, H. Lin, T. Yu and W. Huang, RSC Adv., 2013, 3, 45-49.

19 T. Kuila, S. Bose, A. Mishra, P. Khanra, N. Kim and J. Lee, Prog. Mater. Sci., 2012, 57, 1061-1105.

20 F. V. Ferreira, L. D. S. Cividanes, F. S. Brito, B. R. Canuto de Menezes, W. Franceschi, E. A. N. Simonetti and G. P. Thim, Functionalization of graphene and applications, in Functionalizing graphene and carbon nanotubes, Springer Briefs in Applied Sciences and Technology. Springer, Cham, 2016.

21 L. Gan, S. Shang, C. Wah, M. Yuen and S. Jiang, RSC Adv., 2015, 5, 15954-15961.

22 V. Georgakilas, M. Otyepka, A. B. Bourlinos, V. Chandra, N. Kim, K. Christian Kemp, P. Hobza, R. Zboril and K. S. Kim, Chem. Rev., 2012, 112, 6156-6214.

23 K. G. Nathalie, K. O. Kim, Z. Jiawen, H. Stefan, G. S. Friedrich and B. Christopher, Macromol. Chem. Phys., 2011, 212, 131143.

24 C. Suryanarayana, K. ChowdojiRao and D. Kumar, Prog. Org. Coat., 2008, 63, 72-78.

25 S. Ghosh, Self-healing Materials: Fundamentals, design strategies, and applications, Wiley-VCH Verlag Gmbh \& Co., KGaA, 2009.

26 M. Samadzadeh, S. H. Boura, M. Peikari, S. M. Kasiriha and A. Ashrafi, Prog. Org. Coat., 2010, 68, 159-164.

27 Y. Zhao, J. Fickert, K. Landfester and D. Crespy, Small, 2012, 8, 2954-2958.

28 J. A. Syrett, C. R. Becer and D. M. Haddleton, Polym. Chem., 2010, 1, 978-987.

29 Y. C. Yuan, T. Yin, M. Z. Rong and M. Q. Zhang, eXPRESS Polym. Lett., 2008, 2, 238-250.

30 J. Yang, M. W. Keller, J. S. Moore, S. R. White and N. R. Sottos, Macromolecules, 2008, 41, 9650-9655.

31 G. Deng, C. Tang, F. Li, H. Jiang and Y. Chen, Macromolecules, 2010, 43, 1191-1194.

32 F. Herbst, D. Dohler, P. Michael and W. H. Binder, Macromol. Rapid Commun., 2013, 34, 203-220.

33 S. Burattini, H. M. Colquhoun, J. D. Fox, D. Friedmann, B. W. Greenland, P. J. F. Harris, W. Hayes, M. E. Mackay and S. J. Rowan, Chem. Commun., 2009, 6717-6719.

34 Q. Wang, J. L. Mynar, M. Yoshida, E. Lee, M. Lee, K. Okuro, K. Kinbara and T. Aida, Nature, 2010, 463, 339-343.

35 H. Raghubanshi, S. M. Ngobeni, A. O. Osikoya, N. D. Shooto, C. W. Dikio, E. B. Naidoo, E. D. Dikio, R. K. Pandey and R. Prakash, J. Ind. Eng. Chem., 2017, 47, 169-178.

36 A. Hariharasubramanian and Y. D. Ravichandran, RSC Adv., 2014, 4, 54740-54746.

37 Z. Kachoei, S. Khoee and N. Sharifi, Iran. Polym. J., 2015, 24, 203-217.
38 D. Li, M. B. Müller, S. Gilje, R. B. Kaner and G. G. Wallace, Nat. Nanotechnol., 2008, 3, 101-105.

39 S. Khoee and Z. Kachoei, RSC Adv., 2015, 5, 21023-21032.

40 K. M. Zia, M. Barikani, M. Zuber, I. A. Bhatti and H. N. Bhatti, Iran. Polym. J., 2008, 17, 61-72.

41 S. Khoee and M. Kardani, Eur. Polym. J., 2014, 58, 180-190.

42 S. Pei and H. Cheng, Carbon, 2012, 50, 3210-3228.

43 L. M. Malarda, M. A. Pimentaa, G. Dresselhaus and M. S. Dresselhaus, Phys. Rep., 2009, 473, 51-87.

44 S. Niyogi, E. Bekyarova, M. E. Itkis, H. Zhang, K. Shepperd, J. Hicks, M. Sprinkle, C. Berger, C. N. Lau, W. A. deHeer, E. H. Conrad and R. C. Haddon, Nano Lett., 2010, 10, 4061-4066.

45 T. Kuila, S. Bose, P. Khanra, N. H. Kim, K. Y. Rhee and J. H. Lee, Composites, Part A, 2011, 42, 1856-1861.

46 H. Hu, X. Wang, J. Wanga, L. Wana, F. Liu and H. Zheng, Chem. Phys. Lett., 2010, 484, 247-253.

47 P. Lin, L. Meng, Y. Huang, L. Liu and D. Fan, Appl. Surf. Sci., 2015, 324, 784-790.

48 O. Akhavan, E. Ghaderi, S. Aghayee, Y. Fereydoonia and A. Talebi, J. Mater. Chem., 2012, 22, 13773-13781.

49 Y. Geng, S. J. Wang and J. K. Kim, J. Colloid Interface Sci., 2009, 336, 592-598.

50 C. Chen, Q. Yang, Y. Yang, W. Lv, Y. Wen, P. Hou, M. Wang and H. Cheng, Adv. Mater., 2009, 21, 3007-3011.

51 G. Shao, Y. Lu and F. Wu, J. Mater. Sci., 2012, 47, 4400-4409. 52 K. M. Zia, M. Barikani, I. A. Bhatti, M. Zuber and H. N. Bhatti, J. Appl. Polym. Sci., 2008, 109, 1840-1849.

53 A. Singhal, K. A. Dubey, Y. K. Bhardwaj, D. Jain, S. Choudhury and A. K. Tyagi, RSC Adv., 2013, 3, 2091320921.

54 W. Wang, L. Xu, F. Liu, X. Lia and L. Xing, J. Mater. Chem. A, 2013, 1, 776-782.

55 Y. Wang, J. Yu, W. Dai, Y. Song, D. Wang, L. Zeng and N. Jiang, Polym. Compos., 2015, 36, 556-565.

56 J. Ma, Q. Meng, A. Michelmore, N. Kawashima, Z. Izzuddin, C. Bengtsson and H. Kuan, J. Mater. Chem. A, 2013, 1, 42554264.

57 T. Bai, C. Li, J. Sun, Y. Song, J. Wang, W. J. Blau, B. Zhang and Y. Chen, Chem.-Eur. J., 2015, 21, 1-7.

58 Y. J. Kim, P. H. Huh and B. K. Kim, J. Polym. Sci., Part B: Polym. Phys., 2015, 53, 468-474.

59 P. Kardar, Prog. Org. Coat., 2015, 89, 271-276.

60 P. Cordier, F. Tournilhac, C. Soulie-Ziakovic and L. Leibler, Nature, 2008, 451, 977-980.

61 C. Rodehed and B. Ranby, J. Appl. Polym. Sci., 1986, 32, 33093315. 